\title{
CORRIGENDUM
}

\section{Plant nanobionics approach to augment photosynthesis and biochemical sensing}

Juan Pablo Giraldo, Markita P. Landry, Sean M. Faltermeier, Thomas P. McNicholas, Nicole M. Iverson, Ardemis A. Boghossian, Nigel F. Reuel, Andrew J. Hilmer, Fatih Sen, Jacqueline A. Brew and Michael S. Strano

Nature Materials 13, 400-408 (2014); published online 16 March 2014; corrected after print 21 March 2014.

In the version of this Article originally published, in Fig. $4 \mathrm{k}$, the scale bar should have been $16 \mu \mathrm{m}$, and in the sentence beginning "Leaves assembled with CoMoCAT..." the characteristic fluorescence peak for the $(6,5)$ chirality should have read '(980-1,000 nm)'. These errors have now been corrected in the online versions of the Article. 